\section{O PATHOS NA MÚSICA DO TARDO-RENASCIMENTO - NACHLEBEN DER ANTIKE E CONSTRUÇÃO DE MEMÓRIA}

\author{
Maya Suemi Lemos ${ }^{1}$
}

\section{RESUMO:}

Há pouco mais de um século a historiografia da arte, sobretudo de matriz germânica, parece ter reorientado sua leitura do Renascimento italiano, se debruçando sobre os componentes anticlássicos visíveis na produção não apenas quinhentista, mas também quatrocentista. A partir da perspectiva do historiador Aby Warburg sobre o pathos na arte italiana do Renascimento, fazemos um paralelo com aspectos de determinadas vertentes da música tardo-renascentista. Buscamos atentar para as similitudes e diferenças no processo de sobrevivência ou memória da Antiguidade nos dois respectivos campos da expressão, levantando uma hipótese de leitura de determinados traços da música da vanguarda florentina deste período.

\section{PALAVRAS-CHAVE:}

música italiana no tardo-renascimento; pathos; Aby Warburg; Nachleben e memória.

\section{ABSTRACT:}

Just over a century, art historiography, specially with German origin, seems to have redirected its reading of Italian Renaissance, focusing upon anticlassical components noticeable not only on the production of the 500' but also on the 400'. Following the historian Aby Warburg's perspective on pathos in Italian Renaissance art, we present here a parallel with aspects of certain strands of late Renaissance music. We seek to reveal similarities and differences in the process of survival or memory from Antiquity within both fields of expression, proposing a reading hypothesis of certain traces of avant-garde florentine music of this period.
1. Universidade do Estado do Rio de Janeiro (UERJ). Email: mayasuemi@gmail. com 


\section{KEYWORDS:}

Late-Renaissance italian music; pathos; Aby Warburg; Nachleben and memory.

Durante os seus últimos anos de vida, o historiador da arte Aby Warburg dedicou-se intensamente ao projeto que parecia representar ao mesmo tempo a culminância e a convergência de todos seus estudos anteriores - a montagem do chamado Atlas Mnemosyne. Até a data de sua morte, em 1929, sessenta e três grandes pranchas deste Bilderatlas haviam sido montadas, por meio das quais ele buscava mapear, justapondo imagens, a "sobrevivência" ou a "pós-vida" da Antiguidade - Nachleben der Antike. Tratava-se de buscar entender o processo de reatualização, em diferentes épocas e espaços, de imagens de grande potência simbólica e afetiva que haviam emergido anteriormente na Antiguidade ocidental. De que maneira e por que determinados motivos plásticos ou simbólicos característicos da arte antiga pagã haviam reaparecido nos séculos XV e XVI em obras de artistas como Botticelli, Polaiuolo, Donatello, Ghirlandaio?

Warburg não percebia este reaparecimento unicamente como uma retomada de topoi figurativos, mas, mais fundamentalmente, como a insurgência de fórmulas expressivas de energias primordiais, reativadas pela memória cultural. A $\mathrm{Na}$ chleben para Warburg não significava somente, assim, a sobrevivência de um espírito formal, mas também a memória de uma energia psíquica. Segundo ele, as imagens sobreviviam ou reapareciam como sinais, marcas, "engramas da experiência emotiva", como "patrimônios hereditários" da memória, como exprimira ele na introdução ao Atlas.

Desde seus primeiros estudos, observando pinturas e desenhos de Botticelli, Warburg intuía haver, sob a figuraçáo reiterada de elementos serpenteantes - véus esvoaçantes, cabelos revoltos e corpos ondulantes - uma intenção expressiva de natureza patética. A intensificação visível do gestual, do movimento desses elementos nas figuras femininas seria a tradução plástica de um movimento intensificado, por sua vez sintoma de um pathos. $\mathrm{O}$ historiador se lançava num trabalho ao mesmo tempo minucioso e amplo de identificaçáo das fontes imagéticas antigas nas quais teriam se inspirado os artistas 
do Renascimento, e concluía que eles haviam-se voltado para a Antiguidade náo única e necessariamente em busca de qualidades formais áulicas, apolíneas, de formalizaçóes plásticas nobres e plácidas, equilibradas e racionais, mas também em busca de fórmulas capazes de exprimir um pathos exacerbado, muito mais identificáveis ao componente dionisíaco, até entáo um ponto cego na historiografia da arte antiga. Energias psíquicas primordiais, concluía Warburg, emergem em tempos e geografias distintas, materializadas em determinadas Pathosformeln, figuraçóes plásticas tais como corpos em contorção e agitação, roupas e cabelos movimentados e torcidos pelo vento.

Tratava-se, visivelmente, de calibrar a visão sobre a arte antiga e suas reatualizaçóes, dando ênfase à sua dimensão pulsional, violenta, irracional. Lembremos que Warburg (18661929) pertenceu a uma geração imediatamente consecutiva à de Nietzsche (1844-1900), de quem foi contemporâneo. A influência do pensamento de Nietzsche sobre a sua obra pode ser nuançada, mas não negligenciada. O Nascimento da Tragédia, onde Nietzsche enunciou a oposição dinâmica entre os princípios artísticos apolíneo e dionisíaco da arte grega, é de 1872, vinte anos antes da realização, por Warburg, do estudo "O Nascimento de Vênus e a Primavera de Sandro Botticelli". Numa perspectiva mais ampla, o trabalho de historiografia da arte de Warburg condiz com um ambiente intelectual germânico que, na virada para o século XX e nas suas primeiras duas décadas, operaria uma profunda reavaliação de certas correntes estéticas, sobretudo do maneirismo do século XVI, colocando luz sobre e valorizando filóes de cunho anticlássico que haviam surgido em pleno Renascimento. É neste contexto que, há pouco mais de cem anos, em 1914, o também historiador da arte Walter Friedlaender, em sua conferência inaugural na universidade de Freiburg, trouxe à luz a noção de "anticlássico", buscando afinar e reorientar a crítica sobre a arte maneirista da Itália dos anos 1520 a 1590 . Nesta conferência, posteriormente editada e traduzida, ele abordou o subjetivismo presente na obra de pintores como Pontormo, Rosso Fiorentino ou Parmigianino, que subvertia a estética clássica do segundo Renascimento na modalidade ora de um primitivismo ou de um expressionismo pictórico, ora de uma distorção voluntária das formas. Historiadores da escola vie- 
nense como Alois Riegl e Max Dvorak participavam também, nesta mesma época, desta leitura renovada do maneirismo italiano. $\mathrm{Na}$ esteira de Nietzsche, que mostrara que a arte antiga não fora somente ordem e harmonia áulicas, esforçava-se em evidenciar, no interior mesmo do grande edifício espiritual do Renascimento, veios e tendências anticlássicas, opostas ao espírito apolíneo clássico. Uma forte nuance se colocava aí, assim, entre o conceito de antigo e de clássico.

Percebemos, retrospectivamente, o quanto o substrato tardo-romântico e, mais tarde, expressionista, deu condiçôes espirituais, nestas décadas, para estes processos de reavaliação. E não é de espantar que estes processos tenham emanado justamente do ambiente cultural germânico: estas releituras revelavam, oportunamente, que o vasto patrimônio estético e espiritual da Antiguidade não era, finalmente, tão distinto assim da deutsche Formegefühl, podendo, mesmo, se assimilar, em parte, a ela.

Warburg, de certa maneira, fizera mais do que isso: mais do que assimilar, ou ao menos aproximar uma matriz cultural da outra, ele fez recuar a sensibilidade maneirista pelo movimento e pelo pathos ao quattrocento, provando que ela já estava manifesta em incontáveis imagens, de Pollaiuolo, Botticelli, Ghirlandaio, Giuliano da Sangallo, Donatello, entre outros, contestando a habitudine historiográfica de tomar a descoberta do grupo do Laocoonte em Roma, em 1506, como fator emblemático para o desenvolvimento do gosto maneirista pela expressáo muscular contorcida, serpenteada, figuração por excelência do patético.

Comemorando, então, o centenário deste processo de reavaliação, de calibragem historiográfica, pretendemos relembrar e colocar aqui em foco o equivalente musical deste componente anticlássico identificado tanto por Warburg quanto por Friedlaender, presente em distintos filóes estéticos do seicento musical italiano. Buscaremos mostrar que, também na música, a memória de uma outra Antiguidade é buscada e reivindicada, mais afeita à procura, pelos modernos, de novas (ou antigas) fórmulas patéticas e expressivas.

\section{PATHOS E MÚSICA}

A ideia de uma tradução ou mediação artística de afetos, paixôes é familiar a todo pesquisador e músico habituado a se 
debruçar sobre a música dos séculos XVI a XVIII. Sabemos bem do entusiasmo dos membros da Camerata Bardi, intelectuais e artistas da vanguarda florentina do último quarto dos quinhentos; de sua intenção manifesta de recriar a música dos antigos, supostamente capaz de mover com eficácia os afetos do ouvinte. A tarefa de reativar a memória da Antiguidade, no caso da música, mostrava-se porém mais árdua do que no caso das artes visuais. Pois se os artistas italianos do quattrocento e cinquecento tinham ao alcance dos olhos exemplos visíveis, palpáveis, imediatos de expressóes gestuais dos antigos, preservadas na estatuária, nos frisos das ruínas e sarcófagos romanos, os músicos do cinquecento foram obrigados a contentar-se, em sua tentativa de repristinar a música da Antiguidade, com sistematizaçóes teóricas esparsas e lacunares. ${ }^{2}$

No entender dos mentores intelectuais e teóricos da empreitada florentina de reforma musical, Girolamo Mei (15191594), Giovanni Bardi (1534-1612), e Vincenzo Galilei (1520-1591), o caminho para o resgate das qualidades musicais dos gregos antigos passava por devolver ao texto poético a posição de proeminência frente à música. Segundo a sua leitura de Platão, a música deveria secundar a poesia, ser governada por ela, assim como o corpo pela alma.

(...) al qual proposito ragionando tutti i gran savi, e in particolare Platone, il qual dice, che il cantare deve andare seguitando il verso dal Poeta fatto, addolcendolo con la voce, quasi buon cuoco, che alla vivanda, ch' egli ha bene stagionata, aggiunga qualche poco d'intingoletto, o condimento, per farla al suo Signor parer più grata. Però componendo sopra tutto v'ingegnerete, che il verso ben regolato, e la parola quanto più si possa bene intesa sia; non lasciando traviarvi dal contrappunto, quasi cattivo notatore, che dalla corrente trasportar si lasci, nè arrivi oltre al fine là ove egli proposto s'aveva e tenendo per costante, che così come l'anima del corpo à più nobile; altresì le parole più nobili del contrappunto sono : e come il corpo dell' anima regolato esser deve, così il contrappunto delle parole deve prender norma. Or non parrebbe egli cosa ridicola, se andando in piazza vedeste il servo dal suo Signore essere seguito ad esto comandare ; o fanciullo, che al Padre, o al Pedagogo suo ammaestramento dar ne volesse? Ben conobbe il divino Cipriano verso il fine della sua vita quanto in quei tempi ciò fosse nella Musica gravissimo errore; onde si diede con tutti li nervi dell' ingegno a far bene intendere il verso, e suono delle parole ne'
2. Deixe-se clara aqui a defasagem temporal entre estes processos nos campos, respectivamente, das artes visuais e da música. Pois se nas artes visuais italianas é já no quattrocento que a influência da pintura do norte, flamenga, começa a ceder face ao interesse cada vez mais marcado pela cultura antiga, a influência do modelo polifônico do norte franco-flamengo perdura na música até meados ou mesmo fins do século XVI. Os esforços de repristinação da música da Antiguidade, empreendidos pelos intelectuais florentinos, remontam à segunda metade do cinquecento. 
3. “(...) a respeito do que refletiram todos os grandes sábios, e em particular Platão, que disse dever o canto acompanhar o verso composto pelo poeta, suavizando-o com a voz, como um bom cozinheiro que acrescenta ao alimento bem maturado um pouco de molho ou condimento, para tornálo mais saboroso ao seu senhor. Mas, ao compor, se empenharás para que o verso seja bem proporcionado e para que a palavra seja o mais bem compreendida possível, não deixando-se desviar pelo contraponto como um mal nadador que se deixa transportar pela correnteza e chega a um destino distinto daquele que se propunha. E terás como constante que, assim como a alma é mais nobre do que o corpo, as palavras são mais nobres do que o contraponto. E, assim como o corpo deve ser regido pela alma, o contraponto deve se regrar pelas palavras. Ora, não lhe pareceria ridículo se, andando pela praça, visses o servo ser acompanhado e comandar o seu senhor? $\mathrm{Ou}$ um menino que quisesse educar seu pai ou professor? Bem soube o divino Cipriano, no fim de sua vida, o quanto havia naquele tempo de equívoco na música, empenhando-se com todo seus nervos a fazer bem compreender o verso e o som das palavras em seus madrigais, como se vê naquele a cinco vozes (...)". Nossa tradução. Ver também p. 241: Dico, adunque, che in due parti la Musica usata a questi
Madrigali suoi, come si vede in quello a cinque $(. . .)^{3}$ (BARDI in DONI, 1763, p. 242).

Qualidade essencial do "ben cantare", instruía Bardi em seu Discorso mandato a Giulio Caccini sopra la musica antica e l cantar bene, de 1580, é "fazer entender bem as palavras", e não deturpá-las, como o fazia, segundo ele, a polifonia.

(...) nè vi deve parere mica poco, se in una stanza, che è d'otto versi ne trarrete sedici passaggi vaghi, vari, e dilettevoli, mantenendo il verso libero e bello, e senza nessuno guastamento: e sianvi per esempio quelle non mai a bastanza lodate Signore di Ferrara, alle quali io ho udito cantare più di trecento trenta Madrigali alla mente, cosa miracolosa, nè mai guastare pure una sillaba. Oltre di ciò conviene, se sommo grado di lode in cantando acquistar volete, fare intendere bene le parole, che è sovrana importanza nel caso nostro ${ }^{4}$ (BARDI in DONI, 1763, p. 245).

O texto deveria recuperar sua inteligibilidade quando cantado - condição para cumprir sua função primeira de dirigir, mover o ânimo do ouvinte. ${ }^{5}$

O curioso é que um espírito em muitos aspectos classicizante como o de Bardi nominasse como exemplos positivos do "ben cantare" unicamente o compositor Cipriano de Rore e as "Signore di Ferrara". Pois apontar esses exemplos significava referir-se a um ambiente intelectual, musical e literário - a corte dos Este, de Ferrara - que vinha manifestando, desde meados do século, um gosto pronunciado por uma linguagem musical de forte apelo patético, apoiada num uso afirmado do cromatismo como recurso de impacto expressivo. Uma música experimental, altamente elaborada, refinada e virtuosística, muitas vezes revestindo significados ocultos, composta para o deleite de um círculo restrito de eruditos - a chamada musica reservata. Uma música de qualidades, finalmente, diametralmente opostas ao espírito clássico.

E o compositor táo elogiado por Bardi, Cipriano de Rore (c.1515 - 1565), ativo em Ferrara de 1546 a 1559 (maestro di cappella de Ercole II) pode ser apontado como um precursor deste estilo expressivo (que virá a ser designado, não sem razáo, stilo affettuoso). Rore busca expressar musicalmente cada palavra e ideia presente no texto, não se furtando para isto a utilizar, além de madrigalismos, cromatismos, dissonâncias, 
movimentos harmônicos e melódicos inusitados. Mas Cipriano é apenas o primeiro de uma linhagem, que contava, assim como o círculo de Florença, com um mentor teórico: Nicola Vicentino. Vicentino pretende resgatar da música grega antiga a distinçáo entre os três gêneros musicais - diatônico (o único então em uso), o cromático e o enarmônico. Ele concentra seus esforços sobre o cromático, uma vez que o enarmônico, muito embora devesse ter sido, segundo ele, mais o nobre e refinado, não seria viável no contexto moderno pois dependia da capacidade de percepçáo de intervalos menores do que o semitom, perdida desde a Antiguidade.

(...) perche con effetto comprendono che (come li scrittori antichi dimostrano) era meritamente ad altro uso la Cromatica $\&$ Enarmonica Musica riserbata che la Diatonica, perche questa in feste publiche in luoghi communi a uso delle vulgari orecchie si cantava: quelle fra li privati sollazzi de Signori e Principi, ad uso delle purgate orecchie in lode di gran personaggi et heroi s'adoperavano $^{6}$ (VICENTINO, 1555, fol. 10v).

Para Vicentino, a escala cromática (que envolve semitons consecutivos), associada à escala diatônica em uso, parecia oferecer uma maior variedade de recursos expressivos, aptos a melhor mimetizar a natureza afetiva dos textos poéticos. ${ }^{7}$ As pesquisas de Vicentino influenciaram fortemente o círculo musical de Ferrara, que explorou de maneira bastante radical o potencial expressivo e patético do cromatismo. Orlando de Lasso (1532-1594), muito embora náo tenha estado a serviço dos Este, mas sim dos Gonzaga, foi, ao menos por um período, cultivador da musica reservata, do que são um exemplo fulgurante suas Prophetiae Sibyllarum, provavelmente compostas em torno de 1555-1560. Mencionemos, também nesta linhagem, Luca Marenzio, que esteve em Ferrara entre 1580-1581 acompanhando seu patráo, o cardeal Luigi d'Este, e dedicou a Alfonso II e Lucrezia d'Este dois livros de madrigais. ${ }^{9}$ E, ainda, Giaches de Wert, que viria mais tarde a influenciar Claudio Monteverdi, e Luzzasco Luzzaschi, autor de peças altamente virtuosísticas para o Concerto delle donne, as célebres Signore di Ferrara, mencionadas e elogiadas por Bardi. Uma última figura importante desta corrente anticlássica a mencionar é Carlo Gesualdo que, tendo esposado Leonora d'Este, frequentou o círculo musical de Ferrara e foi tempi si divide, una, che à quella, che contrapunto s'appella; l'altra arte di ben cantare frà da noi nominata. "Digo, ainda, que a música praticada nestes tempos se divide em duas: uma é aquela chamada contraponto; à outra, chamamos arte de bem cantar". Nossa tradução, grifo nosso.

4. "não the deve parecer pouca coisa se, em uma estrofe de oito versos, trouxesse dezesseis passagens graciosas, variadas e agradáveis, mantendo o verso livre e belo, sem nenhuma deturpação. Tome-se por exemplo aquelas nunca suficientemente louvadas Damas de Ferrara, as quais ouvi cantar mais de trezentos e trinta madrigais de cor, coisa miraculosa, sem deturpar uma só sílaba. Além disto convém, se quereis cantando conquistar alto louvor, fazer bem entender as palavras, coisa da maior importância, neste caso". Nossa tradução.

5. atribuindo a Aristóteles: (...) dicendo altrove, a questo proposito, che buon Musico non può esser nomato colui, che non ha forza con l'armonia sua di trar l'animo altrui a qualunque costume. "(...) dizendo em outra parte, a este propósito, que não pode ser chamado bom músico aquele que não seja capaz de dirigir o ânimo dos outros a qual seja maneira". (BARDI in DONI, p. 241). Nossa tradução. 
6. “(...) como demonstram os escritores antigos) a música cromática e enarmônica era reservada a uso distinto da música diatônica. Pois esta se cantava em festas públicas e lugares comuns, para ouvidos vulgares; aquelas eram adotadas nos entretenimentos de senhores e príncipes, para uso de ouvidos refinados, em louvor de grandes personagens e heróis". Nossa tradução. Consultável em edição moderna, na tradução de Maria Rika Maniates, editada por Claude V. Palisca: Ancient Music Adapted to Modern Practice. New Haven and London: Yale University Press, 1996, p. 33.

7. É sua a concepção de um teclado cromático, o archicembalo, que contém todas as notas da escala cromática, permitindo que ela seja utilizada em toda sua extensão e em todos os modos, sem problemas de afinação. Existe um exemplar remanescente deste instrumento: Clave musicum Omnitonum Modulis Diatonicis Cromaticis et Enarmonicis, construído por Vito Trasuntino, Veneza, 1606.

9. Citemos, como exemplos do uso expressivo destes recursos, os madrigais Solo e pensoso $i$ piú deserti campi (Petrarca) e Crudele acerba inexorabil Morte, ambos do Nono libro di madrigali a cinque voci, Veneza, 1599. fortemente influenciado por ele. Seus responsórios de trevas para a sexta-feira santa (Responsoria et alia ad Officium Hebdomadae Sanctae spectantia) sáo exemplos extremados que nos mostram até onde pôde chegar a exploração de sonoridades expressivas, irradiada a partir do ambiente musical de Ferrara.

É importante notar que esta exacerbaçáo patética ocorre sem que se rompa com a estrutura polifônica - os exemplos citados são essencialmente peças polifônicas. A estrutura não é, assim, negada ou recusada, como é o caso na vanguarda florentina, que proporá a via da monodia. Tratava-se, sim, de distorcê-la e dilatá-la por meio de dissonâncias, do cromatismo, de intervalos, contornos e conduçáo melódicos inesperados a favor de uma expressáo mais contundente de affetti e concetti. A favor, em outras palavras, de um subjetivismo expressivo, em muitos aspectos identificável ao caso dos artistas florentinos anticlássicos estudados por Friedlaender nos anos 1910, que citamos no início.

Não podemos esquecer que a Ferrara dos Este é também, e sobretudo, um locus de vanguarda literária. Ariosto esteve sob o patronato do cardeal Ippolito d'Este e, posteriormente, de Alfonso. E Alfonso II $(1533$ - 1597) foi protetor de Torquato Tasso e Guarini. É neste ambiente que são fermentadas as grandes revoluçôes estilísticas literárias entre cinquecento e seicento, e é lá que a cultura cênica pastoral toma seu mais forte impulso. Nestes mesmos meados do século XVI, entre 1543 e 1545, da pena de Giovan Battista Giraldi (1504-1573), entáo secretário privado de Hércules II e depois de Alfonso II d'Este, surge algo totalmente novo: um drama satírico - Egle - criado com a intençáo expressa de renovar seu homólogo grego, acompanhado de um texto teórico, a Lettera sovra il comporre le Satire atte alla scena. Em Egle, Giraldi (que adotou, no âmbito acadêmico, o apelido Cinzio), póe no foco da cena não os pastores, pastoras, ninfas e deidades de ethos apolíneo, personagens da tradição literária e cênica que vem se firmando com força nas cortes italianas, mas personagens do círculo de Dionísio: sátiros, faunos, seres meio animais, lúbricos, violentos, incapazes de controlar suas pulsóes passionais e eróticas, sempre à espreita e prontos a assaltar as ninfas seguidoras de Diana. O nome da personagem que dá título ao drama, Egle, é, não por acaso, o nome de uma das Mênades, ou Bacantes, adoradoras de Dionísio ou Baco. Ora, o que significa resgatar 
sátiros, faunos e demais entidades míticas assemelhadas senão reatualizar a memória do componente náo-clássico da cultura antiga, suas paixóes, sua pulsóes?

Observe-se que esta vasta e notável irrupção de padróes passionais se dá num contexto de construção de uma civilidade cortesã, de estabelecimento e formalização de uma sociedade de corte que implica num controle rigoroso das paixóes, numa domesticação das pulsóes. Neste sentido, a emergência de tais padróes poderia ser tomada como um sintoma das tensóes decorrentes deste processo, sendo eles, assim, materializaçôes formais e estéticas de um instinto reacional. Ernst Gombrich sugeriu, em sua biografia intelectual de Warburg, que o historiador teria visto a Ninfa como "erupção de uma emoção primitiva através da crosta do autocontrole cristáo e do decoro burguês" (apud TEIXEIRA, 2010, p. 142). O prólogo do drama satírico de Giraldi Cinzio nos parece significativo deste processo reacional:

E andando per le selve de l'Arcadia

(Forse per ricrear la stanca mente

Lontan dal vulgo e da la gente sciocca)

Avenne che trovò Pale e Pomona

Ch'avean tenzon d'una gran cosa insieme,

Cioè de la natura. E dicea Pale

Che la natura venia meno e meno

Venian le cose naturali in essa;

Ma Pomona, più saggia, le dicea

Che se 'ngannava e che non era vero

Che la madre natura ristringesse

Punto de la sua ampiezza, e che 'l mutarsi

Era più tosto al liberal, a l'ampio,

Ch'al misero, a lo stretto et a l'angusto;

(...)

Non son, come voi dite, unqua venuti

Ne la natura men satiri e fauni,

Anzi ella ne produce ogni dì molti;

Ma avenuto è, per lor natural uso,

Che' $n$ una gran caverna che prodotta

La natura gli avea son stati in gioia

Il tempo che veduti non gli avete;

E quando gli voleste ne le parti

Vostre raccôr, ve n`avereste molti,

Con gran piacer de la natura istessa. 
Et in fede di questo, i' n'ho veduti,

Venendo qui, gran copia ${ }^{10}$

(GIRALDI CINZIO, 1985 [1545], p. 9-11).

10. "E andando pelas selvas da Arcádia / (Talvez para recrear a mente cansada /Longe do povo e de gente tola) / Aconteceu de encontrar Pala e Pomona, / que discutiam sobre coisa importante, / a natureza. E dizia Pala / que a natureza vinha desfalecendo, / e com ela as coisas naturais; / mas Pomona, mais sábia, lhe dizia / que ela se enganava, que não era verdade / que a mãe natureza diminuísse / em amplitude, e que a mudança / era mais para o amplo e vasto / do que para o estreito e limitado; (...) / não estão surgindo na natureza, como dizeis, / menos sátiros e faunos, / pelo contrário, ela cria muitos todos os dias; / mas ocorreu, em virtude de seus hábitos, / de, em uma caverna que a natureza para eles havia criado, permanecerem felizes / durante este tempo que vocês não os viam; / e quando vocês quiseram trazê-los junto a si, / encontraram muitos deles, / para grande prazer da própria natureza. / E prova disto é que eu os vi / vindo para cá em grande número.” Nossa tradução.

11. "Assim, para lhes dar fé hoje, e para sempre, / de que em sua abundância não decresce / a vasta natureza em nada, / fará [o poeta] virem aqui os sátiros / que no bosque estão, reunidos num tropel. / Mas aquele que de cá se vê / lhes dará
Estaria a natureza (domínio do primitivo, rústico, pulsional) em retração frente ao avanço da civilização (domínio do controle, do artifício)? É o tema que anima a disputa entre Pale e Pomona no prólogo, deixando claro, com seu desfecho, o escopo ético/estético da peça: a marcha da civilidade náo extinguiu a comunidade rústica de sátiros e faunos, assevera o Poeta - juiz da disputa. Ao contrário, a natureza os produz a cada dia mais, afirma ele. "Prova disto é que os vi, em grande quantidade, vindo para cá, conclui o Poeta, fazendo entrar em cena o tropel báquico:

Dunque, per farvi fede oggi per sempre

Che de la sua abbondanza mai non scema

La liberal natura alcuna parte,

Ora i satir venir vi farà inanzi,

Ch'accolti sono in un drappel nel bosco.

Ma costui che di qua viene palese

Farà de l'apparir lor la cagione

Et i capringi dèi ch'uscir vedrete

Vi faran manifesto di che sorte

Di favole sia questa. Or, spettatori,

Se vi sia sempre la natura amica,

Né buon natural manchi a chi n'have uopo,

State cheti et attenti ; e se vi fia

Grato veder di novo questa gente

Di cui credeasi il seme esser già spento,

Fate che sì il poeta se n'aveggia

Che sia costretto anco altra volta darvi,

Per la benignità vostra, piacere ${ }^{11}$

(GIRALDI CINZIO, 1985 [1545], p. 13-14).

Em 1598 a dinastia dos Este se interrompe com Afonso II, que morre sem filhos legítimos, e o Ducado é devolvido aos Estados Pontifícios. A despeito do infortúnio dinástico, o penchant dos círculos literários e musicais estenses pela expressividade, por um pathos exacerbado deixará sua marca na música do século seguinte. Tornemos assim, a Florença, de onde partimos em nossa reflexão. 
Vimos que na teoria e práxis irradiada a partir do círculo de Ferrara acreditava-se que a potência afetiva da música dos antigos poderia ser reativada por meio do resgate ou da reinvenção do gênero cromático, como suplemento de recursos expressivos a ser somado ao sistema em uso. Já para os intelectuais florentinos, embora atentassem, como observamos, para a vertente expressiva, affettuosa de Ferrara, é na clareza da enunciação do texto que lhes parecia abrir-se o caminho para a moção dos afetos. Assim, é perfeitamente compreensível que a via escolhida tenha sido a monodia.

Ora, considerando as reiteradas promessas de uma música mobilizadora de afetos, e a confiança que os membros da Camerata Bardi depositavam na monodia como veículo da expressão destes afetos, somos tomados por certa perplexidade diante das materializaçóes musicais resultantes dos estudos eruditos e das formulações teóricas do círculo florentino. As composiçóes, por exemplo, dos intermédios para La Pellegrina (realizados em fasto como parte dos festejos para as núpcias de Fernando de Médici e Cristina de Lorena, em 1589), as árias de Caccini e Peri, e mesmo o dramma per musica em seus primórdios, a despeito da sua inegável beleza, da revolução musical que significa a recriação da monodia, de sua importância simbólica (a proeminência do indivíduo que exprime seu drama, em primeira pessoa), a despeito, ainda, da extraordinária e engenhosa tradução musical das inflexóes da fala e do texto, são de algum modo decepcionantes se nelas buscamos uma impressão afetiva, uma mobilizaçáo das paixóes do texto, à altura do prometido. As melodias ora finamente ornamentadas, preciosas e graciosas em seus volteios presentes nos intermédios, nas árias de Caccini, ou bem o estilo recitativo puro e rigoroso dos primeiros dramas em música não parecem, ao menos a nossos olhos contemporâneos, capazes de suscitar o efeito tão desejado. Fracasso estético ou bem impossibilidade nossa de compreender esta forma de mimetização emotiva?

Os fastuosos cenários e figurinos confeccionados para os intermédios para La Pellegrina de 1589 não escaparam ao interesse historiográfico de Warburg, que se debruçou detidamente sobre os desenhos, gravuras, relatos e livros de contas, e reconstituiu, em sua totalidade, a sequência dos intermédios, num estudo de 1895. Com boa dose de humor, Warburg descreve os esforços eruditos dos idealizadores dos intermédios e razão de aparecer / e os deuses caprinos que vede sair / lhes mostrarão de que tipo é / esta fábula. Agora, espectadores, / se lhes é ainda cara a natureza, / e se o bom natural falta a quem dele precisa, / ficais quietos e atentos; e se lhes for / grato ver de novo esta gente / da qual se acreditava extinta a estirpe, / fazei percebêlo o poeta / para que se obrigue outra vez a darlhes / pela bondade sua, prazer". Nossa tradução. 
seus figurinos em representar visual e alegoricamente os complexos enredos desenvolvidos. Assim, no primeiro intermédio, temos a seguinte simbologia alegórica:

a música harmoniosa das esferas é gerada da seguinte maneira: do colo da Necessidade descende o fuso adamantino que forma o eixo entre os polos do Universo. As três Parcas - Láquesis, Cloto e Átropos - estão sentadas aos pés de sua mãe, ajudando a girar o fuso e cantando o hino eterno do passado, presente e futuro. Seu canto se mistura com os sons das Sereias, senhoras sobre as oito esferas que giram em torno do eixo do Universo; e assim a harmonia eterna procede do acordo entre a Necessidade e a Natureza (WARBURG, 2013 [1895], p. 348).

Warburg não se interessou em absoluto pela música executada nos intermédios e se preocupou essencialmente com a transposição visual, pelos figurinos e cenários, desta rebuscada alegoria. Uma vez que não havia fala nem ação dramática no intermédio, a compreensão da intrincada simbologia dependia unicamente, em seu entender, de sua transposição em elementos visuais, assim como nos cortejos mudos dos festejos de rua tradicionais florentinos. Assim, Warburg nos explica o que levantou a partir dos relatos e livros de contabilidade de Emilio de Cavalieri, compositor de algumas das peças musicais, mas aqui sobretudo intendente do espetáculo:

(...) No que dizia respeito à sua aparência externa [das Sereias], era necessário que o público percebesse imediatamente duas coisas: que elas possuíam, como aqueles seres míticos parecidos com aves, o poder do canto; e que eram as condutoras das esferas. Chegaram então à seguinte conclusão: como cantoras semelhantes a pássaros, as Sereias receberam um casaco de penas; e como senhoras sobre as esferas, o respectivo signo astral como ornamento para os cabelos.

Com a ajuda dos alfaiates Oreto Berardi e Niccolò Serlori, tentaram então transpor o simbolismo rico, porém demasiadamente sutil, para a realidade concreta dos figurinos. A primeira dificuldade foi o casaco de penas: era impossível fazê-los para quinze Sereias com caríssimas penas reais. No entanto, Francesco Gorini conseguiu encontrar um substituto: em 5 de outubro, recebeu "(...) 53 braccia de tela para que seja pintada a fim de se parecer com penas verdadeiras para 14 figurinos do primeiro 
intermezzo". Como vemos, haveria um elemento de ilusão na apresentação.

Durante todo o mês de outubro e até meados de novembro, os alfaiates trabalharam com grande zelo. No dia 15 de novembro. "99 braccia di tela cilindrata" [tela calandrada] haviam se transformado em (...) "treze corpetes com mangas, meias-mangas, fitas, pequenas asas e outras roupagens para o primeiro interme$z z o "$ (WARBURG, 2013 [1895], p. 356).

Não seria de se espantar se uma transposição assim abstrata fosse mal compreendida pelo público... Warburg continua:

Tudo isso revela a arte e o cuidado aplicado à produção de acessórios adequados e expressivos; e ainda mais erudiç̧ão era necessária para elaborar os atributos da Necessidade.

O desenho de Buontalenti mostra a Necessidade mais ou menos assim como Platão a descreve: ela está sentada em seu trono, o fuso desce na frente dela e é girado pelas três Parcas coroadas e vestidas de branco. Na mão esquerda a Necessidade segura dois grandes pregos; na direita, alguns fios de tripa, e sobre sua cabeça tem uma guirlanda de cipreste. Estes dois últimos atributos não são mencionados por Platão, mas por Horácio, que forneceu a Bardi vários atributos para a Mãe Necessidade (...).

O que em Platão e Horácio haviam sido alegorias profundas, usadas para explicar de modo poético os mistérios da vida, os eruditos do século XVI interpretaram como dados para uma descrição pessoal; assim, os símbolos obscuros transformaram-se em peças de roupa e acessórios explícitos que os cenógrafos e figurinistas afixavam aos atores. Se estes - como era a Necessidade - já tivessem que carregar acessórios em demasia, eram pintados no trono da figura correspondente. Já que as laterais deste, como mostra o desenho de Bardi, eram invisíveis quando visto de frente, o público não os via, mas a consciência do inventor podia ficar tranquila. (...)

Será que todo esse simbolismo forçado e conspícuo capacitou Bardi a esclarecer, pelo menos para a parte culta do seu público, a profunda ideia subjacente em uma composição tấo cuidadosamente elaborada? (WARBURG, 2013 [1895], p. 357-358).

Apesar do empenho na caracterização dos figurinos, dedutíveis dos dados do livro de contabilidade de Emilio de Cavalieri, e do inegável engenho de Bernardo Buontalenti, o significado da cena parece ter permanecido obscuro aos olhos do público. Warburg mostra, transcrevendo os relatos do edi- 
12. Diario descritto da Giuseppe Pauoni delle feste celebrate nelle solennissime nozze delli serenissimi sposi, il sig. don Ferdinando Medici, \& la sig. donna Christina di Loreno gran duchi di Toscana. Nel quale con breuità si esplica il torneo, la battaglianauale, la comedia con gli intermedij, et altre feste occorse di giorno in giorno per tutto il dì 15 di maggio $M D L X X X I X$, Bologna, Giouanni Rossi, 1589.

13. Raccolta di tutte le solennissime feste nel sponsalitio della serenissima gran duchessa di Toscana fatte in Fiorenza il mese di maggio 1589. Con brevità raccolte da Simone Cavallino da Viterbo, Roma, Paolo Blado, 1589.

14. Poesia de Giovanni Bardi; música de Antonio Archilei (1550-1612) ou Emilio de Cavalieri (c.1550-1602). "Das mais altas esferas, / com a cara escolta de sereias celestes, / sou a harmonia que a vós vem, mortais / depois que a alta fama fez saber / que o sol jamais viu tão nobre casal / quanto o vosso, nova Minerva e forte Alcides". Nossa tradução. tor Giuseppe Pavoni (c. 1551-1641) ${ }^{12}$ e de Simone Cavallino ${ }^{13}$, que mesmo espectadores ilustrados como eles tiveram dificuldade em decifrar a ideia central do intermédio - a harmonia do Universo. Ora, tal incompreensão é também um sinal significativo para nós, que, distintamente de Warburg, não negligenciamos a presença da música no espetáculo e nos indagamos aqui sobre a capacidade comunicativa e emotiva das composiçóes que emanavam do círculo de Bardi. Pois este intermédio era, sim, cantado, e seus textos buscavam explicar a cena alegórica:

Dalle più alte sfere

Di celesti sirene amica scorta

Son l'armonia ch'a voi vengo mortali,

Poscia, che fino al ciel battendo l'ali

L'alta fiama n'apporta,

Che mai si nobil coppia 'l sol non vide

Qual voi nova Minerva e fort' Alcide. ${ }^{14}$

Dolcissime Sirene

Tornate al cielo, e'ntanto

Facciam cantando

A gara un dolce canto.

Non mai tanto splendore

Vid' Argo, Cipr' o Delo.

$(\ldots)^{15}$

Noi, che cantando, le celeste sfere

dolcemente rotar facciam intorno

in così lieto giorno

lasciando '1 Paradiso;

meraviglie più altere

cantiam d'una bell'alm' e d'un bel viso. ${ }^{16}$

A se basear na narrativa de Cavallino, nem mesmo as músicas e seu texto foram capazes de esclarecer o sentido da apariçáo espetacular, muito embora elas tenham sido apreciadas. Necessidade, Sereias e Parcas se convertem, na percepção de Cavallino, em "uma senhora vestida de anjo" cantando belíssimas harmonias, "deuses com vestimentas soberbíssimas" e três coros de música: 
Calata la prima tela restò in aria una nube che vi era dentro una Donna da Agnola vestita, che a guisa d'Angiola cantava si sonoro, e con bellissimi concenti che ogn'uno restò maravigliato, e stupido la qual nube, a poco a poco calata spari, e restò la scena con un Paradiso e Cielo che parea si naturale, essendovi le stelle tanto apparenti, che da ciascheduno erano stimate rubate dall'ottavo Cielo. Il Paradiso era ornato di molto numero di Dei con vestiti superbissimi, e vi erano tre Chori di Musiche tutti tre su le nubi (...) ${ }^{17}$ (CAVALLINO, 1589, p. 3).

O sentido do texto poético, que falava de Harmonia universal, de esferas e Sereias, parece ter permanecido obscuro aos ouvidos dos espectadores, tendo-se possivelmente perdido ao longo dos intermináveis ornamentos e melismas vocais das composiçóes. Onde ficava, assim, a clareza do texto, reivindicada de forma tão afirmada pela vanguarda florentina como condição essencial para a expressão e mobilização dos afetos?

A música parece ter sido um ponto cego na leitura de Warburg dos intermédios de 1589. Seu pensamento, mas sobretudo seu estudo sobre as ninfas quatrocentistas, nos inspira, porém, uma hipótese interpretativa deste aparente paradoxo. Giulio Caccini, na introdução à sua coletânea Le Nuove $M u$ siche, se detém longa e minuciosamente na descrição das maneiras de ornamentar o canto. Tal insistência se justifica, segundo ele, por uma intenção de "melhor atender aos objetivos do musicista, que são agradar e mover as paixóes da alma” e de buscar a "maneira mais afetuosa", mais expressiva de cantar. Os exemplos musicais que ele fornece mostram uma busca permanente de intensificação do movimento melódico por meio de diminuiçôes e ornamentaçôes de várias espécies, mas sobretudo pelo uso de notas curtas pontuadas que conferem uma dinâmica sensivelmente mais intensa à melodia, fazendo alternarem-se aceleraçóes e retençóes. Em seu esquema comparativo, o desenho melódico da segunda opção é sempre o melhor, é o que, em suas palavras, contém "maior graça”:
15. Poesia de Cristofano Malvezzi (1547-1597). "Docíssimas Sereias / tornem ao céu; entrementes / façamos, cantando / em duelo, um suave canto. / Jamais tanto esplendor / viu Argos, Chipre ou Delos”. Nossa tradução.

16. Poesia de Cristofano Malvezzi. "Nós que, cantando, as esferas celestes / fazemos suavemente girar, / neste dia tão feliz, / deixando o Paraíso, / mais altas maravilhas / cantamos, com um espírito virtuoso e um belo semblante". Nossa tradução.

17. Idem, p. 3. "Descida a primeira tela permaneceu no ar uma nuvem dentro da qual havia uma senhora vestida de anjo que como anjo cantava, sonoramente e com tão belas harmonias que todos ficaram maravilhados e pasmos. Nuvem que, pouco a pouco abaixada, desapareceu, deixando em cena um paraíso e um céu que parecia tão natural, sendo-lhe as estrelas de tal maneira aparentadas que por todos eram estimadas roubadas do oitavo céu. $\mathrm{O}$ paraíso era ornamentado de grande número de deuses com vestimentas soberbíssimas. E havia três coros de música, todos os três sobre as nuvens (...)". Nossa tradução. 

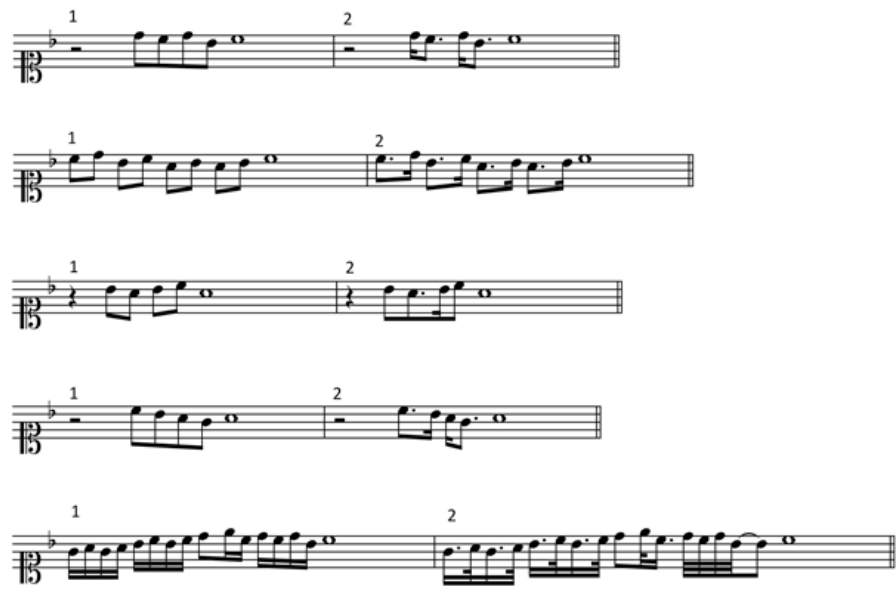

Fig. 1: Giulio Caccini, Le Nuove Musiche, exemplos musicais da introdução "A i lettori" (CACCINI, 1601, p. 8).

A exacerbaçáo do movimento melódico parece ser, para Caccini, um recurso de primeira ordem na expressão patética, do qual ele se esmera em fornecer exemplos nas passagens abaixo, qualificadas por ele de "afetuosíssimas" (passi affettuosissimi):
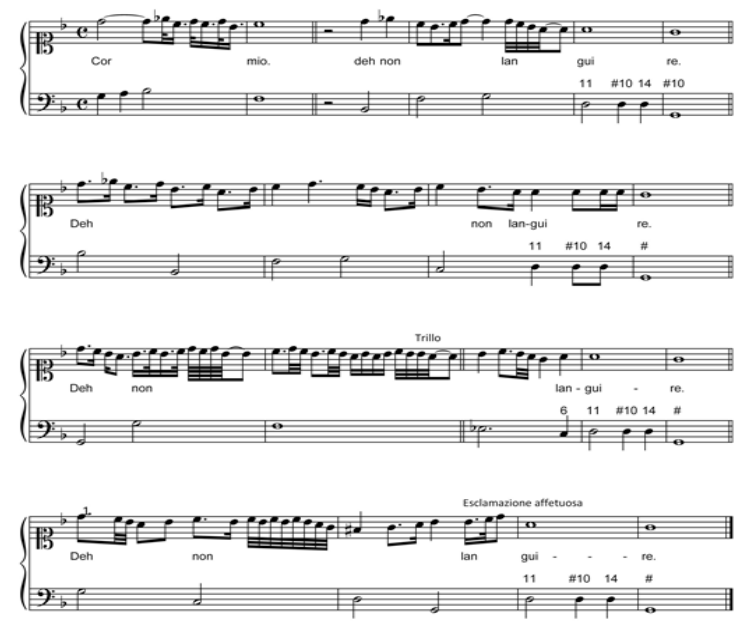

Figura 2: Giulio Caccini, Le Nuove Musiche, exemplos musicais da introdução "A i lettori" (CACCINI, 1601, p. 9).

Se nos fiarmos na coerência do texto de Caccini concluiremos que, em seu julgamento, lá onde há mais graça, há mais movimento. E onde há mais movimento, há mais expressão dos afetos. Não poderíamos, assim, tomar esses volteios vocais refinados e rebuscados (os caccinianos, mas também os dos In- 
termédios para La Pellegrina) como figuraçôes musicais daquela intensificação de movimento que Warburg identificou nos tecidos esvoaçantes das ninfas, interpretando-a como insurgência patética, como sintoma ou marca de um pathos latente? Os volteios vocais não seriam análogos, na cultura expressiva florentina, aos volteios das vestes, cabelos, corpos? Pois Caccini afirma, de fato, ser a ornamentação "a maior parte da graça do canto, capaz de mover os afetos da alma" (1601, p. 6).

Graça e movimento parecem coadunar na cultura do período, como nos confirma o trecho dos Discorsi de 1586 de Annibale Romei, dedicados a Lucrezia d'Este, duquesa de Urbino. contemporâneos à representação dos Intermédios da Pellegrina:

La grazia principalmente si scorge ne' soavi e leggiadri movimenti del corpo, percioché, stando il corpo immobile, ella non è apparente, e quanto a me direi che la grazia non fosse altro che una certa facilità ed agilità che ha il corpo ad ubidir all'anima ${ }^{18}$ (ROMEI, 1586, p.14).

A graça, tão perseguida por Caccini em suas prescriçóes para o ornamento do canto, parece ser, de fato, certa aptidáo ao movimento, a um movimento que obedece ao movimento da alma. Em outras palavras, a capacidade de externar, pelo movimento, os afetos. Voltamos, assim, aos volteios das ninfas - movimentos passionais traduzidos imageticamente em panos e cabelos esvoaçantes, que não sabíamos mais enxergar ou ler antes de Warburg. Movimentos passionais agora traduzidos pelos músicos florentinos do cinquecento em melismas vocais, volteios sonoros que talvez náo tenhamos mais ouvidos para ouvir. Nossa cultura auditiva contemporânea talvez esteja mais apta a identificar a expressão do pathos em dissonâncias, cromatismos, distorçóes harmônicas do que nos ornamentos melódicos. Ou seja, mais na cor, do que na forma.

Mas, por que e por quem se movimentam as ninfas e seus corpos, afinal? Qual motivo, que paixáo se oculta nas bordas do quadro, e só deixa à vista a perturbação gestual sem causa aparente? A que responde a estranha agitação, tão contrastante com a expressão apolínia de seus semblantes? Os movimentos-sintoma nos fazem lembrar que por detrás das árvores e das moitas, sempre à espreita da pureza das ninfas, está a pulsão e a violência dos sátiros ávidos e passionais. $\mathrm{O}$ movi-
18. "A graça se distingue, principalmente, através dos suaves e formosos movimentos do corpo; por que estando o corpo imóvel, ela não aparece; e quanto a mim, direi que a graça não é outra coisa que uma certa facilidade ou agilidade que o corpo tem para obedecer a alma." Nossa tradução. Os Discorsi de Romei se inserem na tradição preceptística inaugurada pelo tratado $I l$ Cortegiano, de Baldassarre Castiglione (1513-1524), consolidadora de uma cultura de corte na Itália renascentista. 
mento intenso de panos, cabelos, corpos, mas também dos ornamentos e volteios vocais - aparentemente gratuitos - dos músicos florentinos desvelam-se como indício, como marca, Nachleben, como memória enfim, de um pathos primordial latente e sempre à espreita. Um pathos ansiado pelos músicos da vanguarda quinhentista, cuja expressão tenderá a ser tomada como a finalidade precípua, como a qualidade primeira da boa música. Se os pintores puderam mirar-se em exemplos helenísticos ou romanos palpáveis, visíveis à luz do sol nas ruínas e vestígios arqueológicos, em seu impulso de dar a ver estes estados anímicos latentes, os músicos precisaram construir praticamente do nada um gestual, uma gesticulação musical própria, capaz de exprimir ou mediar estes mesmos estados, este mesmo pathos. Se os pintores e escultores puderam simplesmente atualizar a memória de fórmulas plástico-corporais patéticas (Pathosformeln), coube aos músicos construir, de seu próprio engenho, esta memória para o campo musical. Uns o fizeram a partir do resgate de sistemas teóricos: o sistema cromático de Vicentino, que nutriu o filáo anticlássico expressivo do ambiente de Ferrara. Outros, a partir da repristinaçáo de uma suposta monodia antiga, ornamentada por uma gesticulação vocal intensificada.

Um outro perfeito contemporâneo de Warburg, Freud (1856-1939), disse, em seus primeiros textos, da memória como construção a posteriori. O termo Mnemosyne, utilizado por Warburg no campo das artes, talvez se adequasse melhor (se tomamos a memória como construção ou transcriçáo do passado) ao caso da arte musical: não apenas mimetizadora ou atualizadora de gestos manifestamente sobreviventes, mas artífice laboriosa de seu próprio passado.

\section{REFERÊNCIAS BIBLIOGRÁFICAS}

BARDI, Giovanni. Discorso mandato a Giulio Caccini sopra la musica antica e 'l cantar bene (Firenze, 1580). In: De' Trattati di Musica di Gio. Battista Doni, Tomo secondo. Firenze: Francesco Gori, 1763, p. 233-248.

CACCINI, Giulio. "A i lettori”. In: Le Nuove Musiche. Firenze, Marescotti, 1601. 
CAVALLINO, Simone. Raccolta di tutte le solennissime feste nel sponsalitio della serenissima gran duchessa di Toscana, fatte in Fiorenza il mese di maggio 1589 / con brevità raccolte da Simone Cauallino da Viterbo. Roma: Paolo Blado, 1589.

GIRALDI CINZIO, Giambattista. Egle (Venezia, 1545). Bologna: Commissione per i testi di lingua, 1985. In: MOLINARI, Carla (ed.). Collezione di Opere inedite o rare. Dispensa CCLXXVI. Bologna. Comissione per i Testi di Lingua, 1985 (Scelta di curiosità letterarie inedite o rare dal secolo XIII al $\mathrm{XIX).}$

GOMBRICH, Ernst. H. Aby Warburg. An Intellectual Biography. London: The Warburg Institute: University of London, 1970.

ROMEI, Annibale. Della Bellezza. In: Discorsi del Conte Annibale Romei Gentil'huomo Ferrarese...divise in sette giornate. Ferrara, Vittorio Baldini, 1586.

TEIXEIRA, Felipe. Aby Warburg e a pós-vida das Pathosformeln antigas. In: História da Historiografia, Ouro Preto, v. 5, set 2010, p. 134-147.

VICENTINO, Nicola. L'antica musica ridotta alla moderna prattica, Roma: Antonio Barre, 1555. Disponível em: http:// gallica.bnf.fr/ark:/12148/bpt6k582234). Acesso: 03 mai 2015.

WARBURG, Aby. Os figurinos teatrais para os intermezzi de 1589 - os desenhos de Bernardo Buontalenti e o livro de contabilidade de Emilio de' Cavalieri. In: A renovação da Antiguidade Pagã - contribuiçóes científico-culturais para a história do Renascimento europeu. Rio de Janeiro: Contraponto, 2013, p. 339-425 (trad. Markus Hediger). 